\title{
A novel potassium ion sensing based on Prussian blue thin films
}

\author{
Kuo-Chuan $\mathrm{Ho}^{*}$, Cheng-Lan Lin \\ Department of Chemical Engineering, National Taiwan University, Taipei, 10617 Taiwan
}

\begin{abstract}
A novel method for sensing potassium ions in aqueous solutions is presented. This method is based on the Prussian blue (PB) modified tin oxide (TO) electrode. Thin films of $\mathrm{PB}\left(\mathrm{KFeFe}(\mathrm{CN})_{6}\right)$, deposited onto transparent $\mathrm{TO}$ substrate, are reduced to Everitt's salt $(\mathrm{ES}$, or $\left.\mathrm{K}_{2} \mathrm{FeFe}(\mathrm{CN})_{6}\right)$ in solutions containing potassium ions. Using an in situ measurement of the absorbance changes in PB thin film while applying different reductive potentials to the electrode, the PB mole fraction within the thin film, $x$, can be obtained for solutions containing various concentrations of potassium ions. By applying either the theory of regular solution $(0.25<x<1)$ or the Margules equation $(0<x<0.25)$ to the Nernst equation, one can construct a special function, which depends mainly on the PB mole fraction and the interaction parameters involved. This sensing method, which eliminates the need for pre-conditioning the electrode to a fixed potential, as proposed previously by other researchers, is based on a linear log-log plot of this special function against the potassium ion concentrations. Such a relationship was observed when the $\mathrm{K}^{+}$concentrations ranged from $3.3 \times 10^{-4} \mathrm{M}$ to $1.0 \mathrm{M}$. The interferences of $\mathrm{Na}^{+}$and $\mathrm{Ba}^{2+}$ on the $\mathrm{K}^{+}$sensing are also studied. (C) 2001 Elsevier Science B.V. All rights reserved.
\end{abstract}

Keywords: Prussian blue; Potassium ion sensing; Margules equation; Regular solution; Modified electrode

\section{Introduction}

\subsection{An introduction to Prussian blue (PB)}

PB has had a long history in both coordination chemistry and as a pigment. PB is well known for many applications, such as ion-selective electrodes [1], electrochromic devices [2], solid-state thin film batteries [3], electrocatalytic reactions [4], photochargeable devices [5] and light-writing materials [6], etc. In many applications, $\mathrm{PB}$ is usually deposited onto conducting substrates, such as platinum or tin oxide (TO), and behaves like an electrodes of the second kind, in which the cell potential depends on the activity of certain ions in the electrolytic solution.

PB is deep blue in color at ground state. Under suitable applied potential it can be reduced to a colorless Prussian white known as Everitt's salt (ES). The reduction of PB to form ES involves the insertion of cations from the contact solution. The reaction equation can be expressed as follows:

$\mathrm{PB}+\mathrm{M}^{+}+\mathrm{e}^{-} \leftrightarrow \mathrm{ES}$

\footnotetext{
* Corresponding author. Fax: +886-2-2362-3040.

E-mail address: kcho@ms.cc.ntu.edu.tw (K.-C. Ho).
}

where $\mathrm{M}^{+}$is the cation in the solution. From the viewpoint of cell structure, $\mathrm{PB}$ has a face-center structure with a unit cell constant equal to $10.2 \AA$ [7]. The radius of the channel formed by the atoms is $1.51 \AA$. Because of this structure, PB acts as a molecular sieve, and the size of the cations inserting into the lattice structure during reduction is then limited. For example, at $\mathrm{pH}=2.0$, the hydrated radii of $\mathrm{K}^{+}$and $\mathrm{Na}^{+}$ calculated from the Stoke's law are 1.25 and $1.83 \AA$, respectively. $\mathrm{K}^{+}$can be inserted into the $\mathrm{PB}$ lattice much easier than $\mathrm{Na}^{+}$[8]. Because of the characteristics mentioned above, PB modified electrodes can be regarded as permselective membranes that possess ion-selectivity during insertion into the PB lattice. PB can therefore, be used as a sensing material in an ion-selective electrode.

$\mathrm{K}^{+}$sensing methods based on metal hexacyanoferrate thin films have been reported [1,9]. In these researches, the metal hexacyanoferrate modified thin film electrodes were subjected to electrochemical or chemical pre-conditions before $\mathrm{K}^{+}$sensing. The potential was measured just before the films deviating from the pre-conditioned state. Because two $\mathrm{K}^{+}$sensing steps are involved and the potential is usually not reproducible, these methods are very difficult. In this research, a new potassium ion sensing method based on PB thin film involving a one-step absorbance measurement is described. The interference of other cations in the solution is discussed. 


\subsection{Theory of the $K^{+}$sensing}

The reaction that reduces $\mathrm{PB}$ to $\mathrm{ES}$ in solutions containing $\mathrm{K}^{+}$can be expressed as

$\mathrm{PB}+\mathrm{K}^{+}+\mathrm{e}^{-} \leftrightarrow \mathrm{ES}$

Applying the Nernst equation to Eq. (2) gives

$E=E^{0}+\frac{R T}{F} \ln \frac{a(\mathrm{~PB}) a_{\mathrm{K}^{+}}}{a(\mathrm{ES})}$

where $a(\mathrm{~PB})$ and $a(\mathrm{ES})$ refer to the activities of PB and ES in the thin film, respectively. $E$ is the potential applied to the electrode, and

$E^{0}=\frac{-\mu^{0}(\mathrm{ES})+\mu^{0}(\mathrm{~PB})+\mu^{0}\left(\mathrm{~K}_{(\mathrm{aq})}^{+}\right)}{F}$

where $\mu^{0}(i)$ is the standard chemical potential of species $i$. Because of the similarity between the structure of PB and ES, a mixture of these two compounds can be regarded as a solid solution. According to the previous works, the behavior of the PB and ES mixture can be described by the theory of regular solutions [10]. The activities of PB and ES can be expressed as follows:

$a(\mathrm{~PB})=x \exp \left(\frac{w(1-x)^{2}}{R T}\right)$

$a(\mathrm{ES})=(1-x) \exp \left(\frac{w x^{2}}{R T}\right)$

where $x$ is the mole fraction of PB in the thin film and $w$ the molar interaction energy. By substituting Eqs. (5) and (6) into (3), the Nernst equation can be rearranged as follows:

$E=E^{\prime}-\frac{R T}{F} P^{\mathrm{I}}(x)$

where

$P^{\mathrm{I}}(x)=\ln \frac{1-x}{x}+z(2 x-1)$

$E^{\prime}=E^{0}+\frac{R T}{F} \ln a_{\mathrm{K}^{+}}$

$z=\frac{w}{R T}$

For sensing the $\mathrm{K}^{+}$concentration in solutions, Eq. (7) can be further rearranged as follows:

$\ln a_{\mathrm{K}^{+}}=\frac{F}{R T}\left(E-E^{0}\right)+P^{\mathrm{I}}(x)$

so that a linear relationship between $\ln a_{\mathrm{K}^{+}}$and $P^{\mathrm{I}}(x)$ can be obtained. If we apply a potential $(<0.6 \mathrm{~V}$ versus $\mathrm{Ag} / \mathrm{AgCl})$ to the $\mathrm{PB}$ modified electrode in solutions containing $\mathrm{K}^{+}$, according to Eq. (3) the value of the PB activity ratio to $\mathrm{ES}$ in a thin film will change. Because the thin film absorbance is proportional to the PB mole fraction in the thin film, the absorbance will also change. For different concentrations of $\mathrm{K}^{+}$in the solution, the change in absorbance is different. Thus, if the $z$ value in Eq. (8) is known, the $\mathrm{K}^{+}$concentration in the solutions can be detected based on Eq. (11) by applying a constant potential to the electrode.

\section{Experimental}

All chemicals used were reagent grade and were not further purified. De-ionized water was used throughout. Transparent conducting TO glasses were used as the electrode for $\mathrm{K}^{+}$sensing. TO glasses were obtained from a local supplier (Sinonar Corporation, Hsinchu, Taiwan). The sheet resistivity of the $\mathrm{SnO}_{2}$ film was $15 \Omega / \square$. TO glasses were washed in $0.1 \mathrm{~N} \mathrm{HCl}$ and de-ionized water using an ultrasonic cleaner for $15 \mathrm{~min}$. The TO glasses were then stored in air before use. The geometric area for PB thin film deposition was $2 \mathrm{~cm}^{2}(1 \mathrm{~cm} \times 2 \mathrm{~cm})$. A conventional three-electrode system was used. A platinum electrode with a geometric area of $0.25 \mathrm{~cm}^{2}$ was used as the counter electrode. A potassium chloride saturated silver-silver chloride electrode $(\mathrm{Ag} / \mathrm{AgCl})$ was used as the reference electrode, all potentials were recorded and reported with respect to this electrode.

Deposition of the PB thin films on TO glass was based on the modified procedure of Itaya et al. [11], the so-called electrodeposition-galvanostatic method, ED-G. The plating solution was prepared from an equivolume mixture of $20 \mathrm{mM} \mathrm{K}{ }_{3} \mathrm{Fe}(\mathrm{CN})_{6}$ and $20 \mathrm{mM} \mathrm{FeCl}_{3}$ aqueous solutions containing $0.1 \mathrm{M} \mathrm{HCl}$ and $0.1 \mathrm{M}$ in $\mathrm{KCl}$. The current density used was $20 \mu \mathrm{A} / \mathrm{cm}^{2}$. PB thin films were washed with deionized water after deposition and stored in air several days before use. The electrode was cycled 10 times between 0.6 and $-0.2 \mathrm{~V}$ (versus $\mathrm{Ag} / \mathrm{AgCl}$ ) in $1 \mathrm{M} \mathrm{KCl}$ before use in order to ensure potassium ion insertion into the thin film.

The voltammetric measurements were carried out with the usual three-electrode configuration. An Eco Chemie (PGSTAT30) instrument was used to control the potential applied to the electrode. A UV-VIS spectrophotometer (Shimatzu, Model UV-1601PC) in combination with the above-mentioned potentiostat was used to record the in situ PB thin film absorbance changes under various applied voltages. The potassium ion sensing experiments were carried in a measuring cell placed inside the UV-VIS spectrophotometer. The apparatus set-up is shown in Fig. 1.

\section{Results}

\subsection{Governing equation for $\mathrm{K}^{+}$sensing}

Before proceeding with the $\mathrm{K}^{+}$sensing, a governing equation, which can describe the behavior of $\mathrm{PB}$ thin film in solutions containing different concentrations of $\mathrm{K}^{+}$, is required. The extent of the $\mathrm{PB}$ reduction depends upon the potential applied to the electrode and the $\mathrm{K}^{+}$concentration 


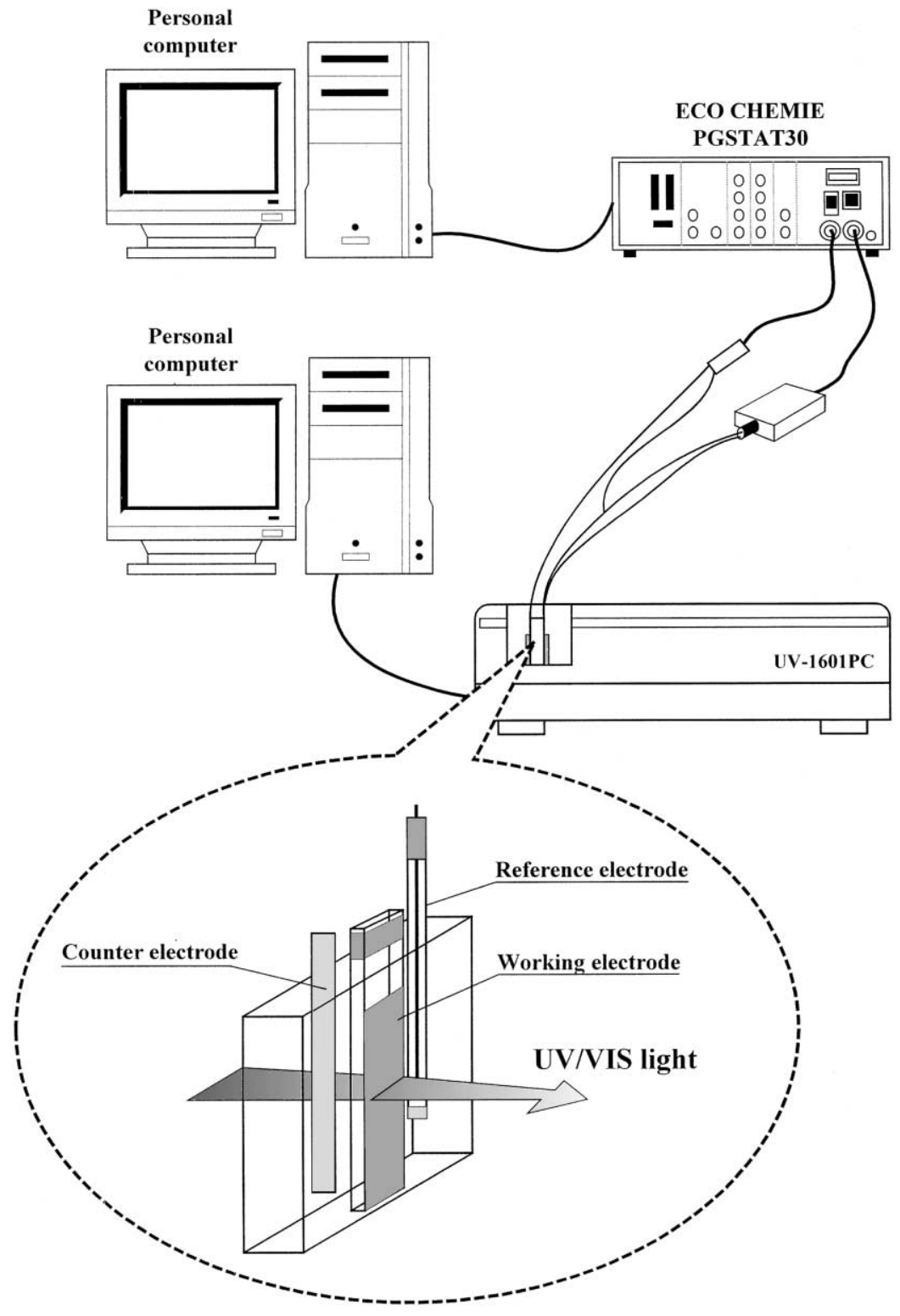

Fig. 1. The apparatus for $\mathrm{K}^{+}$sensing.

in the solution. If a constant potential is applied to the electrode, the $\mathrm{K}^{+}$concentration can be measured by monitoring the extent of the $\mathrm{PB}$ reduction. A relationship between the PB mole fraction in the thin film, $x$, and the potential applied to the electrode, $E$, should be established first. According to Eq. (7), in order to establish the relationship between $P^{\mathrm{I}}(x)$ and the potential applied to the electrode, $E$, the values of $x$ and $E^{\prime}$ must be obtained.

According to the early studies on the electrochemistry of PB thin film [10], the partially reduced PB behaves like a solid solution, and the absorbance of the thin film at $700 \mathrm{~nm}$ is directly proportional to the mole fraction of $\mathrm{PB}, x$, which can be expressed as

$x=\frac{A-A_{\min }}{A_{\max }-A_{\min }}$ where $A$ is the absorbance of the thin film, $A_{\max }$ and $A_{\min }$ are the absorbance of the thin film measured at the electrode potentials set at 0.6 and $-0.2 \mathrm{~V}$ versus $\mathrm{Ag} / \mathrm{AgCl}$, which correspond to the pure PB and ES states of the thin film, respectively. The $\mathrm{PB}$ mole fraction within the thin film can be obtained by monitoring the change in absorbance.

For solutions containing different $\mathrm{K}^{+}$concentrations, the values of $E^{\prime}$ can be obtained from the average values of the cathodic and anodic peak potentials in the cyclic voltammograms. Fig. 2(a) shows the cyclic voltammograms of the PB electrode in solutions containing $1,10^{-1}$, and $10^{-2} \mathrm{M}$ $\mathrm{K}^{+}$. The scan was run slowly at $1 \mathrm{mV} / \mathrm{s}$ in order to ensure equilibrium conditions. The $E^{\prime}$ values were evaluated from the mean values of the paired peak potentials, with a good linear relationship against $\log C_{\mathrm{K}^{+}}$with a slope $=53.2 \mathrm{mV} /$ $\mathrm{p} C_{\mathrm{K}^{+}}$, as shown in Fig. 2(b). The slope is somewhat smaller 

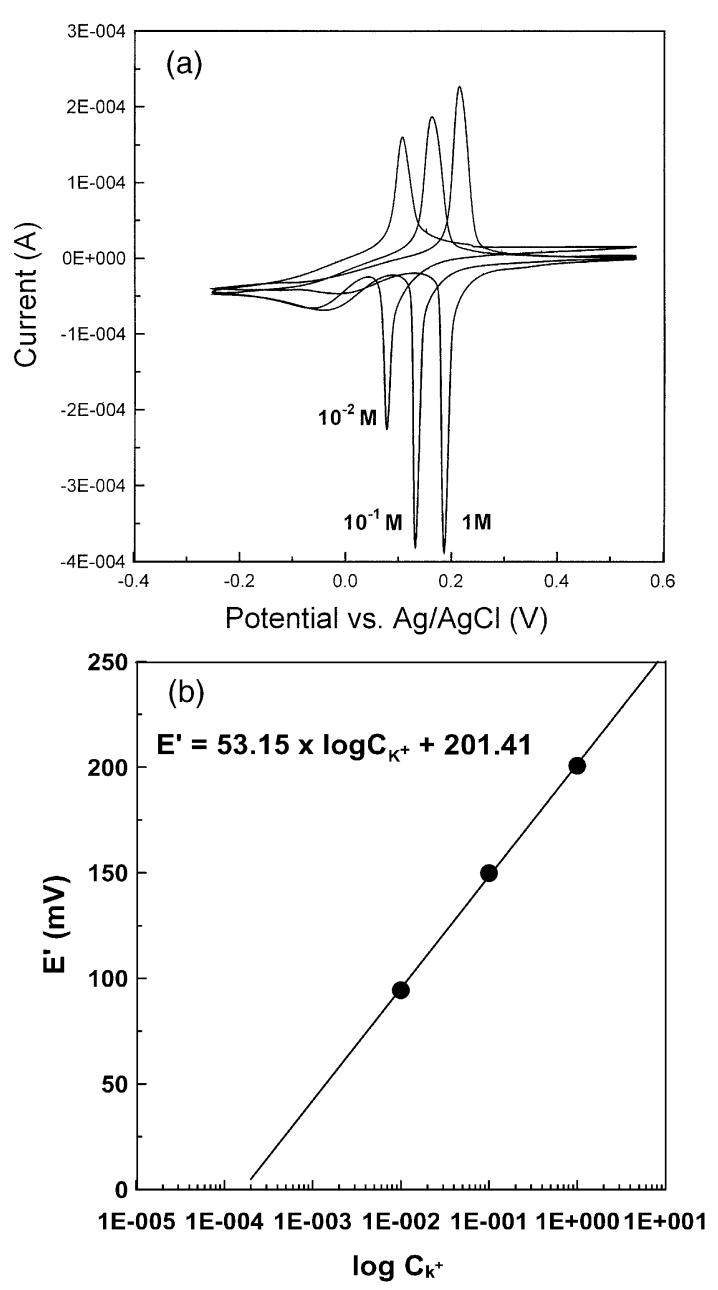

Fig. 2. (a) Cyclic voltammograms of $\mathrm{PB}$ modified electrode in solutions containing $1 \mathrm{M}, 10^{-1} \mathrm{M}$, and $10^{-2} \mathrm{M} \mathrm{K}^{+}$. Scan rate $=1 \mathrm{mV} / \mathrm{s}$; (b) The relationship between $E^{\prime}$ and $\log C_{\mathrm{K}^{+}}$.

than $58.8 \mathrm{mV} / \mathrm{p} C_{\mathrm{K}^{+}}$, as obtained by Krishnan et al. [1] or the ideal Nernst slope $\left(59.2 \mathrm{mV} / \mathrm{p} a_{\mathrm{K}^{+}}\right)$. This may result from the resistance of the substrate or some unknown side reaction during the reduction and oxidation reactions.

By using the experimental data from $x$ and $E^{\prime}$, the value of $z$ in Eq. (8) can be estimated. Eq. (7) was chosen as the governing equation for $\mathrm{K}^{+}$sensing. For the plot of $x$ versus $E$, Eq. (7) fits the experimental data well with $z=1.25$ for $0.25<x<1$ but fails for $0<x<0.25$, as shown in Fig. 3 . To make the comparison easier, the deviation from the regular solution behavior is only illustrated by the dashed curve for the $\mathrm{K}^{+}$concentration of $1 \mathrm{M}$. In fact, this is true for $0<x<0.25$, regardless of the $\mathrm{K}^{+}$concentration. In order to fit the experimental data for $0<x<0.25$, we introduce the Margules equation [12] to describe the behavior of the solid solution. According to the Margules equation, the activity coefficients of PB and ES can be expressed as follows:

$\gamma_{\mathrm{PB}}=\exp \left[(1-x)^{2}\left(A_{12}+2\left(A_{21}-A_{12}\right) x\right)\right]$
$\gamma_{\mathrm{ES}}=\exp \left[x^{2}\left(A_{21}+2\left(A_{12}-A_{21}\right)(1-x)\right)\right]$

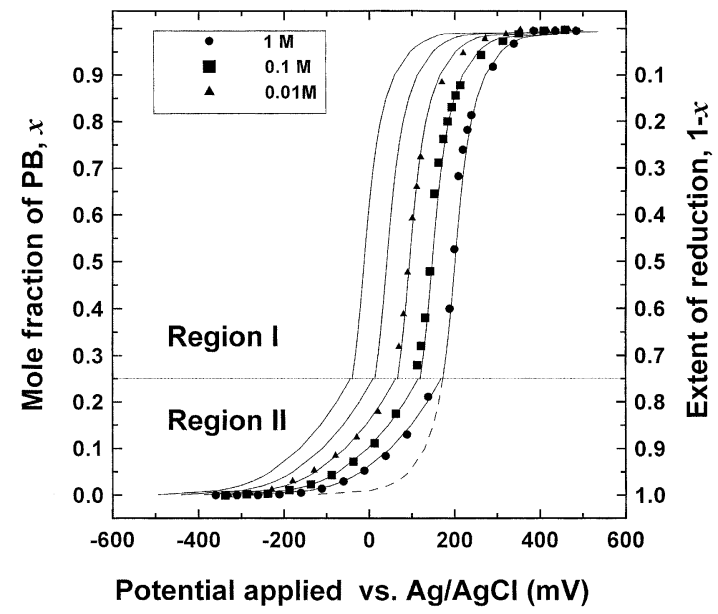

Fig. 3. Mole fraction of PB within the thin film vs. potential applied to the electrode in solutions containing different $\mathrm{K}^{+}$concentrations. The dashed curve was calculated using Eq. (7) for $\mathrm{K}^{+}$concentration of $1 \mathrm{M}$ only. The solid points are experimental values. The solid curves in region I and region II are calculated from Eqs. (7) and (15), respectively. For region I, the parameter used is $z=1.25$, while for region II, the parameters used are $A_{12}=-1.25$ and $A_{21}=2.5$.

where $A_{12}$ and $A_{21}$ are constants. Since $a=\gamma C$, using Eqs. (13) and (14), the Nernst equation can again be rearranged as follows:

$E=E^{\prime}-\frac{R T}{F} P^{\mathrm{II}}(x)$

where

$P^{\mathrm{II}}(x)=\ln \frac{1-x}{x}+A_{12}(x-1)(1-3 x)+A_{21}(3 x-2) x$

and the governing equation for $\mathrm{K}^{+}$sensing is simply replacing the $P^{\mathrm{I}}(x)$ term in Eq. (11) by $P^{\mathrm{II}}(x)$ as

$\ln a_{\mathrm{K}^{+}}=\frac{F}{R T}\left(E-E^{0}\right)+P^{\mathrm{II}}(x)$

Fitting of Eqs. (7) and (15) into the experimental data is also shown in Fig. 3 for regions I and II, respectively. Eq. (15) fits the experimental data well with $A_{12}=-1.25$ and $A_{21}=2.5$ for $0<x<0.25$. Thus, the changing characteristics of the PB mole fraction in solutions, containing different $\mathrm{K}^{+}$ concentrations under various applied potentials, are governed by two equations, namely, Eq. (7) with $z=1.25$ in region I for $0.25<x<1$, and Eq. (15) with $A_{12}=-1.25$ and $A_{21}=2.5$ in region II for $0<x<0.25$.

\section{2. $K^{+}$sensing}

When a potential $(<0.6 \mathrm{~V}$ versus $\mathrm{Ag} / \mathrm{AgCl})$ is applied to the $\mathrm{PB}$ thin film electrode in solutions containing $\mathrm{K}^{+}, \mathrm{PB}$ is immediately reduced and the absorbance of the thin film, as well as the PB mole fraction, decreases. Different extents of $\mathrm{PB}$ reduction can be achieved depending upon the potential 


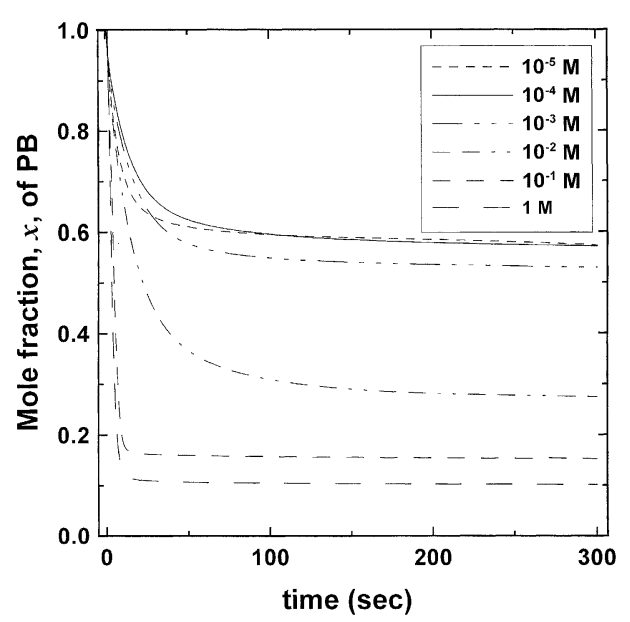

Fig. 4. The mole fraction of $\mathrm{PB}$ in response to various $\mathrm{K}^{+}$concentrations. Potential applied to the electrode was $0.2 \mathrm{~V}$ vs. $\mathrm{Ag} / \mathrm{AgCl}$.

applied and $\mathrm{K}^{+}$concentration in the solution. Upon applying the potential, the PB mole fraction in the thin film responds to the $\mathrm{K}^{+}$sensing, as shown in Fig. 4. A steady-state response can always be reached in $60 \mathrm{~s}$ for $10^{-5} \mathrm{M}$ $<C_{\mathrm{K}^{+}}<1 \mathrm{M}$. The higher the $\mathrm{K}^{+}$concentration in the solution, the shorter the time needed to reach the steady state. By evaluating the PB mole fraction, $x$, through the change in thin film absorbance, the calibration curves can be established by plotting $P^{\mathrm{I}}(x)$ or $P^{\mathrm{II}}(x)$ against $\log C_{\mathrm{K}^{+}}$. For different applied potentials, depending on the PB mole fraction measured, a suitable governing equation is chosen to construct the calibration curves. In Fig. 5, when $0 \mathrm{mV}$ (versus $\mathrm{Ag} / \mathrm{AgCl}$ ) is applied to the electrode, a linear relationship between $P^{\mathrm{II}}(x)$ and $\log C_{\mathrm{K}^{+}}$is observed for $3.3 \times 10^{-2} \mathrm{M}<C_{\mathrm{K}^{+}}<1.0 \mathrm{M}$. However, when 100, 150, and $230 \mathrm{mV}$ (versus $\mathrm{Ag} / \mathrm{AgCl}$ ) are applied to the electrode, a linear relationship between $P^{\mathrm{II}}(x)$ and $\log C_{\mathrm{K}^{+}}$can be extended for $3.3 \times 10^{-4} \mathrm{M}<C_{\mathrm{K}^{+}}<1.0 \mathrm{M}$.

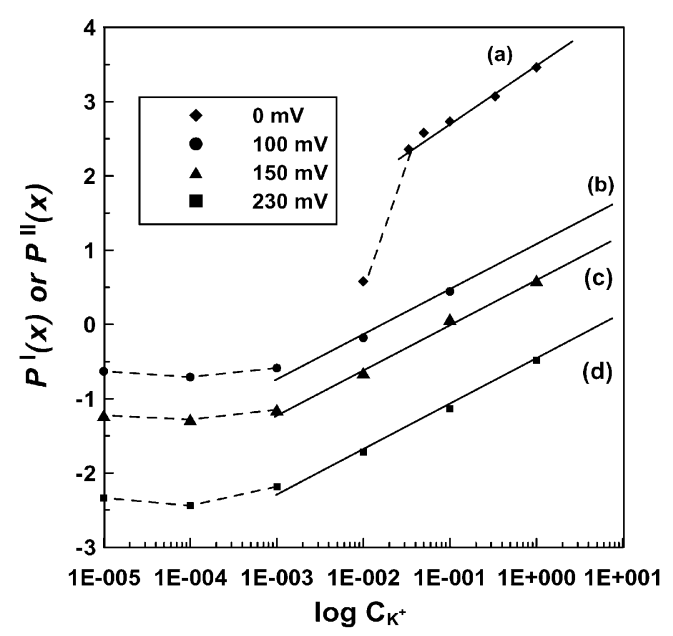

Fig. 5. The plot of $P^{\mathrm{I}}(x)$ or $P^{\mathrm{II}}(x)$ against $\log C_{\mathrm{K}^{+}}$while (a) $0 \mathrm{mV}$; (b) $100 \mathrm{mV}$; (c) $150 \mathrm{mV}$; (d) $230 \mathrm{mV}$ vs. $\mathrm{Ag} / \mathrm{AgCl}$ were applied to the $\mathrm{PB}$ modified electrode in solution containing different concentrations of $\mathrm{K}^{+}$.

\section{Discussion}

\subsection{The sensing limit for $\mathrm{K}^{+}$}

The sensing limit is reached under two conditions: (1) the $\mathrm{K}^{+}$concentration in the solution is too low; and (2) the PB reduction driving force is too large. There must be cations inserted into the PB lattice while a driving force is applied to the electrode. If only low concentrations of $\mathrm{K}^{+}$exist in the solution, $\mathrm{K}^{+}$cannot be transported in time to satisfy the electroneutrality requirement, so other cations, such as $\mathrm{H}^{+}$, are forced to insert into the $\mathrm{PB}$ lattice. As a result, the $\mathrm{K}^{+}$ insertion is no longer the major contribution to the reduction, and the sensing limitation is reached. For solutions with low $\mathrm{K}^{+}$concentrations, because the sensing limit is reached, the change in absorbance (corresponding to the mole fraction of $\mathrm{PB}, x$ ) becomes indistinguishable. The sensing limitations shown in Fig. 5 were reached for this reason, as shown by the dashed curves in (b), (c), and (d). Because the potential ( $<0.6 \mathrm{~V}$ versus $\mathrm{Ag} / \mathrm{AgCl}$ ) applied to the electrode can be regarded as a driving force for $\mathrm{PB}$ reduction, a more negative applied potential corresponds to a larger driving force. The $\mathrm{PB}$ thin film could crash when a more negative potential is applied to the electrode. PB thin film dissolving into the solution can be observed under these conditions. The dashed line in curve (a) in Fig. 5 shows this kind of sensing limit.

It is also noticed that, when a more negative potential is applied to the electrode, PB thin films, deposited by the constant potential method always crashed easier than those deposited by the ED-G method. When the thin film crashes, the blue material from the surface of the PB thin film dissolves into the solution. If a larger driving force is used during $\mathrm{K}^{+}$sensing, the hydrated $\mathrm{K}^{+}$ion will be inserted into the $\mathrm{PB}$ lattice with higher mobility. The induced stress within the PB lattice will then become greater. Since thin films deposited by the ED-G method occurs much slower than the constant potential method, the PB molecules have plenty of time to rearrange the lattice structure in a more ordered way. This means that the thin films are more compact than those deposited by the constant potential method, thus can stand longer during $\mathrm{K}^{+}$sensing.

\subsection{The interference of other cations on $K^{+}$sensing}

Although the channel formed by the PB lattice structure acts as a molecular sieve, hydrated cations with radii larger than $1.51 \AA$ are difficult to insert into the lattice [8]. The existence of other cations, with radii larger than $1.51 \AA$, in the analyzed solution could still interfere with the $\mathrm{K}^{+}$ sensing. The insertion of these cations can still take place under the same two conditions for reaching the sensing limitation, but with a somewhat different mechanism. In the case when a large driving force is applied to the electrode, because of the need for quick cation insertion, other cations in the solution with radii not far larger than $1.51 \AA$ can be forced to insert into the PB lattices. Although the insertion of 


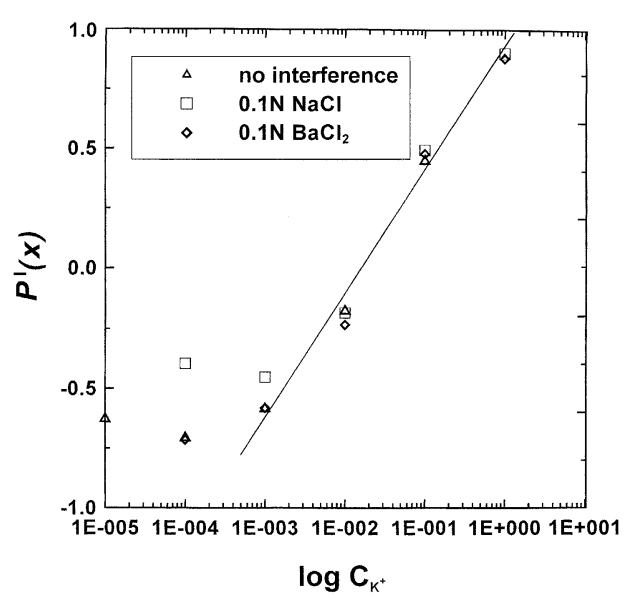

Fig. 6. The sensing of $\mathrm{K}^{+}$with interfering cations. The potential applied to the electrode was $0.1 \mathrm{~V}$ vs. $\mathrm{Ag} / \mathrm{AgCl}$.

other cations can reduce $\mathrm{PB}$, the reaction apparently becomes irreversible, as the reduced $\mathrm{PB}$ thin film is unable to re-oxidize to its ground state. If the concentration of $\mathrm{K}^{+}$in the solution is too low, the $\mathrm{PB}$ reduction must take place while the potential $(<0.6 \mathrm{~V}$ versus $\mathrm{Ag} / \mathrm{AgCl})$ is applied. If there is not enough $\mathrm{K}^{+}$for the PB reduction in the solution, other cations can also be forced to insert into the $\mathrm{PB}$ lattices. The interference of $\mathrm{Na}^{+}$and $\mathrm{Ba}^{2+}$ on $\mathrm{K}^{+}$sensing are shown in Fig. 6. The existence of $0.1 \mathrm{~N} \mathrm{Na}^{+}$in the solution lowers the limit of $\mathrm{K}^{+}$sensing to about $2 \times 10^{-3} \mathrm{M}$. There was almost no interference on the $\mathrm{K}^{+}$sensing caused by the existence of $0.1 \mathrm{~N} \mathrm{Ba}^{2+}$. The Stoke's law radii calculated from the limiting mobility are $1.25,1.83$, and $2.81 \AA$ for $\mathrm{K}^{+}$, $\mathrm{Na}^{+}$, and $\mathrm{Ba}^{2+}$, respectively [8]. The smaller interference of $\mathrm{Ba}^{2+}$ on $\mathrm{K}^{+}$sensing can be expected when comparing that of $\mathrm{Na}^{+}$on $\mathrm{K}^{+}$sensing. Moreover, it can also be expected that the interference of cations will be greater if the radii of their hydrated ions are closer to that of the sensed ion.

\section{Conclusions}

A new method of potassium ion sensing based on PB thin film involving a one-step absorbance measurement is described. For different potentials applied to the electrode during $\mathrm{K}^{+}$sensing, a suitable governing equation with unique parameters can be chosen to construct the calibration curves. In this study, the fact that a mixture of PB and ES can be described by the regular solution model, when the extent of reduction lies between 0 and 0.75 , is reconfirmed. The Margules equation is successfully employed as a governing equation for $\mathrm{K}^{+}$sensing while the extent of reduction lies between 0.75 and 1.00. A linear calibration curve can be established for $3.3 \times 10^{-4} \mathrm{M}<C_{\mathrm{K}^{+}}<1.0 \mathrm{M}$.

The cause of sensing limitations is explained by the ease of cation insertion during PB reduction. The sensing limit is reached for very low concentrations of $\mathrm{K}^{+}$in the solution or an excessive applied driving force. Crashing or dissolving of the PB thin films is observed when the sensing limit is reached. The structural difference of the $P B$ thin film can also influence the sensing limitation. The PB thin films deposited by the constant potential method always crashed easier than those deposited by the ED-G method. Other cations in the solution, such as $\mathrm{Na}^{+}$and $\mathrm{Ba}^{2+}$, will influence the $\mathrm{K}^{+}$sensing and cause irreversible reduction of the PB thin film.

\section{Acknowledgements}

This work was sponsored by the National Research Council of the Republic of China under contract number NSC 87-2214-E002-034.

\section{References}

[1] V. Krishnan, A.L. Xidis, V.D. Neff, Prussian blue solid-state films and membranes as potassium ion-selective electrodes, Anal. Chim. Acta 239 (1990) 7-12.

[2] K. Itaya, K. Shibayama, H. Akahoshi, S. Toshima, Prussian bluemodified electrodes: an application for a stable electrochromic display device, J. Appl. Phys. 53 (1982) 804-805.

[3] M. Kaneko, T. Okata, A secondary battery composed of multilayer Prussian blue and its reaction characteristics, J. Electroanal. Chem. 255 (1988) 45-52.

[4] K. Ougra, N. Endo, M. Nakayama, H. Ootsuka, Mediated activation and electroreduction of $\mathrm{CO}_{2}$ on modified electrodes with conducting polymer and inorganic conductor films, J. Electrochem. Soc. 142 (1995) 4026-4032.

[5] M. Kaneko, K. Takahashi, E. Tsuchida, A photochargeable device composed of bilayer membranes of poly(3-methythiophene) and Prussian blue, J. Electroanal. Chem. 227 (1987) 255-258.

[6] M. Nishizawa, S. Kuwabata, H. Yoneyama, Photoimage formation in a $\mathrm{TiO}_{2}$ particle-incorporated Prussian blue film, J. Electrochem. Soc. 143 (1996) 3462-3465.

[7] J.F. Keggin, F.D. Miles, Structures and formula of the Prussian blues and related compounds, Nature 137 (1936) 577-578.

[8] K. Itaya, T. Ataka, S. Toshima, Spectroelectrochemistry and electrochemical preparation method of Prussian blue modified electrodes, J. Am. Chem. Soc. 104 (1982) 4767-4772.

[9] D. Engel, E.W. Grabner, Copper hexacyanoferrate-modified glassy carbon: a novel type of potassium-selective electrode, Ber. Bunsenges. Phys. Chem. 89 (1985) 982-986.

[10] D. Ellis, M. Eckhoff, V.D. Neff, Electrochromism in the mixedvalence hexacyanides. 1. Voltammetric and spectral studies of the oxidation and reduction of thin films of Prussian blue, J. Phys. Chem. 85 (1981) 1225-1231.

[11] K. Itaya, T. Ataka, S. Toshima, Electrochemical preparation of a Prussian blue analogue: iron-ruthenium cyanide, J. Am. Chem. Soc. 104 (1982) 3751-3752.

[12] J.M. Prausnitz, R.N. Lichtenthaler, E.G. de Azevedo, Molecular Thermodynamics of Fluid-Phase Equilibria, 2nd Edition, PrenticeHall, Englewood Cliffs, NJ, 1996, p. 213.

\section{Biographies}

Кио-Chuan Ho received his BS and MS degrees in Chemical Engineering from National Cheng Kung University, Tainan, Taiwan, in 1978 and 1980, respectively. In 1986, he received the $\mathrm{PhD}$ degree in Chemical Engineering 
at the University of Rochester. The same year he joined PPG Industries, Inc., first as a Senior Research Engineer and then, from 1990 until 1993, as a Research Project Engineer. He has worked on the electrochemical properties of various electrode materials. He has applied surface science/ interfacial engineering and electrochemistry/electrochemical engineering principles for improving the performances of sensor devices, with emphasis on electrochemical, at-rest, and thermal stabilities. Following a 6-year industrial career at PPG Industries, Inc., he joined his alma mater, National Cheng Kung University in 1993 as an Associate Professor in the Chemical Engineering Department. In 1994, he moved to the Department of Chemical Engineering at National Taiwan University. Currently, he is a Professor there.

Cheng-Lan Lin received his BS degree in Chemical Engineering from National Cheng Kung University, Tainan, Taiwan, in 1994. He obtained his MS degree in Chemical Engineering from National Taiwan University, Taipei, Taiwan, in 1996. Currently, he is a $\mathrm{PhD}$ candidate at the Department of Chemical Engineering, National Taiwan University. His research interests include modified electrode applications and ion-selective electrodes. 